Proceedings of the 50th Hawaii International Conference on System Sciences | 2017

\title{
Material Intelligence: Cross-Organizational Collaboration Driven by Detailed Material Data
}

\author{
Esko Hakanen \\ Ville Eloranta \\ Pekka Töytäri \\ Aalto University \\ Aalto University \\ Aalto University \\ ille.eloranta@aalto.fi pekka.toytari@aalto.fi \\ Risto Rajala \\ Aalto University \\ Taija Turunen \\ risto.rajala@aalto.fi \\ Aalto University
aija.turunen@aalto.fi
}

\begin{abstract}
The application of the Internet of Things (IoT) technologies has the potential to reshape inter-organizational collaboration across industries. This study explores the influences of the use of IoT for information sharing in the steel industry networks. Shared data may have multiple uses, including optimization, integration, automatization, and adaptation of objects in their environments. To date, research on IoT has mainly proposed its use in independent nodes and clusters possessing excessive data from their own actions. Conversely, our study emphasizes the benefits that accrue from intensified collaboration. Our findings emphasize that IoT enabled material intelligence can restructure the existing steel industry networks. This can be achieved by bridging the structural holes in the inter-organizational networks.
\end{abstract}

\section{Introduction}

The ability to trace and track items effectively has been a hot topic in the manufacturing industries. This would mean improved productivity, minimized stocks sizes, and reduced lead times for manufacturing companies. The current discussion focuses on the product level, referred to as intelligent products [35], that enable closed loop product life cycle management to fill these targets [27]. Products that collect and carry information about themselves enable a number of services that facilitate the product usage [33]. They offer potential for cross-organizational collaboration, even beyond the product level.

Increasing information intensity of products and processes is visible in many industries. For example, in the steel industry, commoditization of products is forcing companies in developed market areas under a serious pressure to improve their competitiveness [13]. It is increasingly difficult for the incumbents to gain lead through traditional sources of positioning-based competitive advantage [37], as their rivals are offering similar products with lower costs and constantly diminishing the gap on product quality. The urgency for corrective actions and the need for new ways to do business has been evident for some time [13,31].

For steel companies, one potential solution to this commoditization lies in the emerging Internet of Things (IoT) concept. The basic concept of IoT is to enable a variety of things or objects to interact with each other through unique addressing schemes and to cooperate with their neighbors in order to reach common goals [5]. This increases the information intensity of objects and has potential to change our everyday life by making it possible to connect diverse material things to networks $[7,30]$. In particular, for the steel industry actors, the emergence of the IoT hints that materials themselves should be connected to a dedicated database, resulting in intelligent materials, which couple each unique item with its detailed material data, such as exact composition, strength, elasticity, and production history. The collaborative benefits in this approach expand as more and more companies adopt the IoT solutions into their operations. We refer to this possibility as material intelligence.

Networks in which information is not shared, become dense with structural holes. A structural hole is a gap between two actors with complementary resources or information [8]. Therefore, successful bridging of structural holes provides both social capital [10] and economic potential [49]. Despite having mutual interests, many attempts at improving information sharing between steel industry actors have failed due to the lack of legitimacy and trust [31]. IoT offers a way to deal with these issues, as it makes it easier to identify and link the complementary resources and information in the company networks. That way, bridging of structural holes can facilitate cross-organizational collaboration.

Our research aims to incorporate three concepts, structural holes, IoT, and material intelligence. The combination can help to explain how the companies can create value through cross-organizational collaboration. We investigate the phenomena with a qualitative case study, with the following research question: How can steel industry actors find novel incentives for 
cross-organizational collaboration with material intelligence? We found that companies can use the shared information to optimize their processes. In addition, they can reach a mutual understanding of the potential value of IoT data, helping to dispel issues on legitimacy and trust.

The empirical investigation was carried out as a qualitative case study within a steel industry network. Our data consists of a total of 34 interviews, which include interviews with the focal case company, its key stakeholders, and companies that provide complementary offerings for the industry actors.

\section{Background for the Research}

The background of our research consists of three parts. The first one introduces the concept of structural holes and discusses its relevance to business practice. Second, we discuss how products and materials could be incorporated to the IoT. Third, we describe how the two concepts can be harnessed for inter-organizational collaboration.

\subsection{Structural holes and information flows}

Bridges over structural holes yield important benefits. In social networks, the bridge is formed by a third party, called tertius, who is positioned between two or more players [8]. The tertius gains information from both sides, but more importantly, controls the information flow between the two sides and thus benefits from acting as a bridge between the network of actors, groups or activities. The possibility to form a bridge indicates a presence of a discontinuity between exchange relations (i.e., a structural hole) in the network [9]. Originally, the structural hole was identified as a source of social capital, defined as "friends, colleagues, and more general contacts through whom you receive opportunities to use your financial and human capital" [8:9]. In turn, social capital refers to actors' ability to benefit simply from participating in social networks or other social structures [39]. However, social capital is considered to be jointly owned by all the parties in the relationship and no party can have exclusive ownership rights to it $[8,36]$. Social capital has value in use, but it cannot be easily traded between parties [36].

Structural holes are relevant to competition in information intensive business environments. The end customer experiences value in complementary products that work seamlessly together $[41,44]$, i.e., in products which demonstrate successful bridging of structural holes [44]. In general, the structure of the economic network defines "where and whom new opportunities lie" [19:360]. Acting as the bridge provides the actor access to multiple sources of information and alternative ways of thinking, which in turn has proved to be a source of innovation [10,44]. It has been demonstrated that a company with greater breadth of innovation objectives and knowledge sources may achieve better innovation success [29]. Direct and indirect ties between companies expand the diversity of the company's information sources and improve subsequent innovation output [1]. This highlights the potential that the bridging of structural holes can have in facilitating cross-organizational collaboration.

\subsection{Products and materials in the Internet of Things}

Materials have an integral role in all manufacturing processes. Information about them is critical to process and product quality, often with a considerable financial impact for companies [45]. Therefore, not only products, also materials should be incorporated to the IoT. In line with intelligent products discourse [35], we propose an aligning concept of intelligent materials. These are material objects, which can be uniquely identified and coupled with their virtual counterparts $[7,17,35]$. Based on the unique identity, intelligent materials could provide us detailed material data of them, in other words, information about their condition, history, and properties.

We see intelligent materials to honor the underlying goal of IoT, of having a variety of things or objects interacting with each other [5]. The idea is in line with the concept of product intelligence [33], which incorporates product orders, actual products, and further information into one system. Product intelligence relies on intelligent products, a concept with a wide range of definitions [26,27,33,34,35]. However, all these definitions agree on a common underlying assumptionthe objects need to be uniquely traceable. This is achieved by requiring a basic level of intelligence in the products that can be achieved using items such as RFID (Radio Frequency Identification) tags $[17,27,28,33,35,38]$. But this approach is only able to feature products, which are capable of managing their own information, as otherwise a product "can hardly be called intelligent" [35:140]. Therefore, the classifications need to be adjusted, in order to also incorporate simple, but unique items, including pieces of material.

The ability to integrate data to the material itself would be a logical step in the advancing IoT development. The data can be utilized in every part of the cycle from manufacture all the way to recycling and, ideally, utilized in further development of future products [40]. 
There already exist companies that run business using this thought. For example, Granta Design sells solutions for material information management that are marketed to enable better, greener, and safer products for the companies [45].

To maximize its value potential, the material information is forwarded along the supply chain and updated during the life cycle of a product [27]. The amount of data being provided and that is accessible throughout the whole process flow is increasing, but it is being transmitted using separate systems $[4,44]$. At the moment the machinery discusses rather universally across the factory floor, but the material has hardly any role in this system. Most existing systems are designed for the needs of a single actor and the gathered data is utilized only in a small, concentrated part of the whole life cycle of the product [23]. As the complexity of networks formed by both objects and people continue to increase, the number of potential connections will rise. This anticipates networks filled with structural holes.

\subsection{Material intelligence derives from bridg- ing of structural holes in industry networks}

The developing IoT technologies have potential to become crucial technological drivers for information exchange. Based on our research, we underline the potential that lies in cross-organizational collaboration to utilize information brokerage on a system-wide level. Our findings are in line with existing research that has proposed how collaboration between supply chain partners is more effective than supply chain integration [25].

The existing research is making progress in acknowledging the role of structural holes for business performance. Companies have been identified to enhance their performance by bridging structural holes and, furthermore, companies that bridge structural holes in their network have been identified to perform better than their equivalents [49]. By enabling new information flows and connections companies can generate themselves a competitive advantage [19]. In order to utilize these possibilities, a structural hole can be bridged by introducing novel enabling technologies or by providing systemic innovations $[22,44]$. As for the technological side, the development of IoT shows a lot of promise in enabling novel information flows $[5,30]$. In turn, the information can help to change the established practices of industries or facilitate complementary products through systemic innovations [42].

Bridging of a structural hole equals to combining existing actors and actions in a novel way. In turn, technological innovations are known to bring together ideas from different contexts and combining them in a novel way [22]. Therefore, companies that confluence several industries are able to broker their knowledge from multiple industries to create novel business concepts [49]. This resembles business model innovation, as companies try to either create a new market, or create and exploit new opportunities in the existing markets [3]. We posit that in order to construct an innovative business model, companies can bridge a structural hole in two ways: by innovating new products or services, which enable novel possibilities $[3,49]$, or by combining two (or more) existing operations in a novel way, stimulating further systemic innovations $[32,42]$.

In collaboration, companies can bridge structural holes in their networks with material intelligence. This is achieved when the companies utilize the unique identity of intelligent materials to conduct data sharing among organizations [33]. Bridges over structural holes benefit the network actors through fast access to new and diverse information that drives product and service innovations $[22,49]$. Therefore, it can be argued that when the companies collaboratively bridge the structural holes in their networks, some of them have to forfeit benefits that could be accrued from asset protection $[37,43]$. However, in these situations the benefits that accrue from increased trust, better collaboration routines, and reduced opportunism outweigh the disadvantages [1]. It seems that material intelligence provides potential for new business model innovations in the manufacturing industry.

\section{Research Methodology}

Our case study of the steel industry investigated the benefits that could be generated with material intelligence. In particular, we examined how steel industry actors are approaching material intelligence in their operations. The steel industry was selected as the target of this research, since it comprehensively portrays the imminent IoT transition that is ongoing in several industries. The interdisciplinary background of this study rationalizes the application of abductive approach [11] in the analysis, since the study combines literature from different fields and streams, including sociology, business, and organizational sciences.

\subsection{Case description}

The IoT can change manufacturing on all the parts of the value chain. It has the potential to change the structure of the whole industry. Steel products are typically considered as simple and highly uniform products, but now they are going through fundamental 
changes. Steel product manufacturers are forced to compete in an environment defined by fierce competition and low margins, with products that are hard to differentiate due to rigid standards and customers that tend to prefer products that are already familiar to them. It is understandable how the industry is intrigued by the prospected transformation of steel products.

This study explores the influences of the IoT in the steel industry and, specifically, how a European-based company MaterialCo (a pseudonym) has approached the topic. The company pursues the concept which they label as "steel as a message carrier" (SMC). Together with their partners, MaterialCo is constructing a collaborative inter-organizational network that utilizes detailed material data throughout the life cycle of the material and the derived products. The detailed material data helps the downstream actors to fine-tune their processes, whereas MaterialCo gets valuable feedback from their products from their actual usage. In addition to the focal case company, we held interviews with companies in its industry network.

\subsection{Data collection and analysis}

The research followed an iterative process, which involved continuous revision for the collected data, and emphasized on the iterative nature [11]. In systematic combining we gathered knowledge from the empirical world, the case environment, theory, and the outlining framework to direct further research [11]. We considered all material as usable data [20], i.e., combining interviews, observational data, workshop meetings, surveys, and public material. The main data source of this research was interviews, but other data sources were used to confirm the validity of the findings made through triangulation [48].

The interviewees were chosen based on their position and experience in relation to the topic of the study. The case study followed a purposive sampling [12] and semi-structured interview approaches [48], and the interviews were adapted based on previous responses. The interviewees from MaterialCo represented a diverse group across the firm, including highlevel managers, customer-side employees (e.g., product experts), and industry experts. The interview data were collected in the period between February 2014 and April 2015. We held interviews with the representatives of MaterialCo $(n=20)$, its key stakeholders $(n=6)$, and companies that provide complementary offerings for industry actors $(n=8)$. The interviews were recorded and subsequently transcribed. Most of the interviews were conducted face-to-face. All interviewees were offered anonymity.
In order to broaden the perspective of the study, other data sources (field notes, workshops, and company materials) were used to complement the interview material. This was conducted to verify the observations done during this research process.

The data were analyzed with an abductive method. An abductive analysis of the material involves simultaneous data collection and theory development, focusing on the active interconnection between the two [11]. The data were categorized and dimensioned to identify both similarities within each group and intergroup differences [12]. We used cross-case synthesis for primary analysis technique [48], where the findings from each case could be aggregated by comparing the results to other cases [12]. This method results in revealing similar themes across the cases and the differences among cases, while analyzing the reasons for those differences, resulting in the identification of the common themes that are relevant to the case [48].

\section{Empirical Findings}

Our empirical research produced three main findings that describe why the actors are interested in interorganizational collaboration and how this can be achieved with material intelligence.

\subsection{Changes in the offerings and the competi- tive structure of the industry}

The first finding adheres to the extant view that the steel industry actors are facing stern challenges. Competing with product quality is becoming increasingly difficult due to commoditization and lowering margins.

"The customer is unwilling to pay extra for the better quality [i.e., smaller variance], although they desire to attain it (Production manager, MaterialCo)."

Like many industry actors $[6,13]$, the focal case company MaterialCo has sought to resolve these challenges in their offerings by emphasizing the role of services in their product sales.

"When customers are deciding which material to use, they don 't buy just product, they buy a combination of the product and services (Director, MaterialCo)."

However, the company's shift toward services has not completely resolved their challenges. As a result, discussion related to IoT has made them rethink their strategy. The focus on services has helped MaterialCo to learn from their customers' needs and to identify a specific demand for a new type of product, "steel as a 
message carrier" (SMC). In other words, their customers seem to be interested in more refined data that would help in optimizing their process.

"[In SMC concept,] the steel plate would contain the same information than the printed data sheet, which is included in delivery (Development manager, MaterialCo)."

"They [customers] are ready to pay for such raw materials that produce higher-quality products, less wastage, and more accurate audit trails (Director, MaterialCo)."

In addition, other companies in MaterialCo's network voiced their interest for SMC concept. The companies have identified potential uses for MaterialCo's data later on in the value chain.

"The manufacturers are interested on where the steel sheet is originated, to know its historical process data, in order to better control their own process (CEO, Company $A)$."

"The bending machinery needs material information and if the material would know a little more about its properties, the machinery could be further automatized and the possibility for human error diminishes (Systems design manager, Company K)."

MaterialCo's SMC concept is similar to what we portray as material intelligence in this paper. SMC could provide important possibilities in all the phases of a product's life cycle. To fulfill its potential, the database needs to be constantly updated along with the different steps in the item's value chain. SMC can benefit the downstream companies when optimizing their production and many informants highlighted the potential value to other parties.

\subsection{Obstacles in creating material intelligence}

We found three clear obstacles for a holistic system of material intelligence. Most noticeably, the case companies have had a narrow focus, as they have evaluated how material intelligence could provide tools for value chain optimization in the past. Conversely, more recently they have looked more open for more collaborative solutions. For instance, they have acknowledged the value of customer feedback on the performance of a product and the potential for helping the customer in running their process more smoothly.

"More direct collaboration will help us in developing products that bring value to our customers (Service director, MaterialCo)."

When different companies seek to resolve the same underlying issue with different premises, an abundance of rivaling solutions is inevitable. Incorporating the IoT or material intelligence with all the existing enterprise resource planning software is challenging, let alone the integration of different systems.
"In principle, we have all the necessary instructions and information available. It is only question of how to distribute the data along with the steel, and how to incorporate the data to customers' own processes (Service director, MaterialCo)."

Second important obstacle seems to be the different perceptions in data valuation, when designing systems for material intelligence. As a rule of thumb, the case companies perceive their own data as valuable assets and believe that others will pay for their data, at least in the future. Simultaneously, they are unwilling to buy data from others, although they would like to get that information free of charge.

"I feel that workshop companies expect to make substantial business on the data they collect from their own machinery [i.e., installed base] (Systems design manager, Company K)."

"We figured that we should make money by selling the information our machinery collects. We had some nice things, but no one wanted to pay for them (Mining technology director, Company $M$ )."

Third, there is a disagreement on technological solutions. According to case evidence, there seems to exist a strong contradiction in views between the business and engineering sides. The business side is eager to bring the most advanced and sophisticated gadgets to the system, while the engineering side is adamant that such systems are too susceptible to failure in steel industry processes.

"Industrial internet has huge potential and a lot of applications can be devised with a completely new approach. It may revolutionize the current models. [...] At the moment, the executive level talks lot about industrial internet but these talks have not realized in production processes (CEO, Company H)."

"We would need the information from usage, for instance, in heavy wear applications at mines, to monitor the durability, performance and wear. We could attach monitoring sensors to the equipment, but the sensors will break in those conditions (Application manager, MaterialCo)."

\subsection{Material intelligence based on SMC}

Despite the obstacles, we found promise in the situation. To date, the existing literature describing the business potential of IoT $[7,38]$ has focused on systems that rely on smart objects. This view has been dominant also in the discourse related to enabling IoT through different wireless sensor technologies $[5,7,30]$. However, the system for material intelligence does not need smart products or complex systems, since the dominant criterion is the uniqueness of items, not smartness. 
"Just by using a combination of unique ID [identity] and URI [Uniform Resource Identifier] the objects could be globally unique (CEO, Company A)."

SMC concept is targeted to utilize very simple methods. It consists of simple markings (e.g., barcode labels, laser engravings, or synthetic DNA) and the corresponding database entries. This means that material intelligence can be equally well achieved by using very simple methods. This is great news for the steel industry, considering their interest to adopt IoT in their processes. SMC concept requires objects, which are unique, not intelligent per se. The same observation has been stated previously, although less precisely, in a different context [16].

The interviewed companies are very eager to explore potential solutions for the SMC concept. Their view for simplicity was further justified during the conducted interviews and workgroup meetings. For the steel industry actors, the business potential in material intelligence seems to derive, as an integral part, from the variety of data sources. The companies see a lot of potential in combining different information sources, and are eager to build new businesses on it.

"We can effectively combine all this data from different sources [...] to produce something bigger and interesting [as a result] (CEO, Company F)."

\section{Discussion}

The results of our study indicate that companies can bridge structural holes in their network with material intelligence. This helps the companies to share relevant information, thus decreasing the information asymmetry between processes, departments, actors, and clusters. It guides the operation toward more collaborative approach.

\subsection{Material intelligence as a tool for cross-or- ganizational collaboration}

To date, different actors of the steel industry have not been able to agree on a method to share information. They have been unable to see the mutual benefits of the system and have focused on a small part of the entire value chain, resulting in inability to create desired universal systems $[31,40]$. In addition, as our findings indicated, the actors have perceived their information to be valuable, but at the same time, have refused to pay to receive information from others. Clearly, the companies need to be able to identify the mutual benefits of collaboration, before they are willing to participating in the information sharing.

MaterialCo's SMC concept can bridge the structural holes in the industry network. As the structural hole theory suggests [8], by making new connections between different groups an integrator can leverage this position [10] and turn it into business potential [36]. By bridging the structural holes of the industry, the companies can improve their processes and incorporate IoT solutions to existing products. This could provide a possibility to generate mutual benefits that can be universally adopted and enable the needed investments to be made incrementally. In addition, the dense collaboration can ease any issues on data ownership $[21,46]$, as companies aim for mutual benefits.

The case companies agreed that the relation between materials and information will intensify in the future. With SMC companies can generate material intelligence, when material can be combined with its exact properties or data which is accumulated over its life cycle. In particular, our findings show the importance of cross-organizational collaboration in the process. Perhaps most notably, the study findings indicate that complex objects are not a necessity in designing systems for material intelligence. The objects do not need to be smart, only unique.

\subsection{Material intelligence in practice}

After the case data were analyzed, we could form an illustration of the MaterialCo's SMC concept, depicted in Figure 1. The illustration was later presented to case companies in order to validate it. Figure 1 demonstrates how a SMC material can deliver messages that provide a substantial potential for collaborative benefits throughout the assets' life cycle. The value chain in Figure 1 is simplified, but it includes most of the steps that steel products undergo during their life cycle. In a similar fashion to product intelligence [33], material intelligence couples the digital and virtual counterparts of a physical product [17]. This can enable possibilities that remain yet to be unknown. In Figure 1, outer arrows indicate information that is exported to the supporting database from each process step, whereas inner arrows refer to information that is retrieved prior to next step in the value chain (marked with large arrows).

Based on the insights from our case, material intelligence has considerable potential to contribute to all the steps of the steel value chain depicted in Figure 1. The information may help companies to optimize their own processes, but also opt to make adaptations that are meant to ease the processes of other actors. In Figure 1 different actors in the value chain could both provide and receive information related to their operations with material intelligence.

As an illustrative example, consider the manufacturing of a car and its hood plate. In Figure 1, the value chain begins at top, from casting at a foundry. The next 
steps are to produce sheets of steel after rolling and cutting. In result, each sheet has its unique exact composition and properties (within standards), which affect the following process steps. As our interviewee's mentioned, bending is one of them. A company producing the hood can utilize the exact material properties (e.g., yield strength), when shaping the plate to its final form. Then, in welding step, it is crucial to know if the material has high carbon content near the surfaces. Later, car is assembled and shipped to its new owner. In material intelligence, the components used in this specific car are documented to its bill of materials. During the years of use, the car undergoes a variety of maintenance services, but typically the hood plate remains unchanged. After the vehicle gets discarded, the material information can be utilized in both dismantling and sorting of the scrapped materials. Later, the information can be used when producing new steel from the recycled material. It is very relevant information for the foundry to know the composition of its raw material, in order to gain it exactly right for the end products. Currently, without this information, foundries simply have to adjust the batch during the process through trial and error. Furthermore, the information that is accumulated throughout the life cycle can provide valuable feedback for the upstream actors in the value chain when designing new products.

As the results of this study indicate, the biggest challenges of the system are not technical. The system for material intelligence would require the implementation of both the identification system and the supporting database. In order for the material intelligence

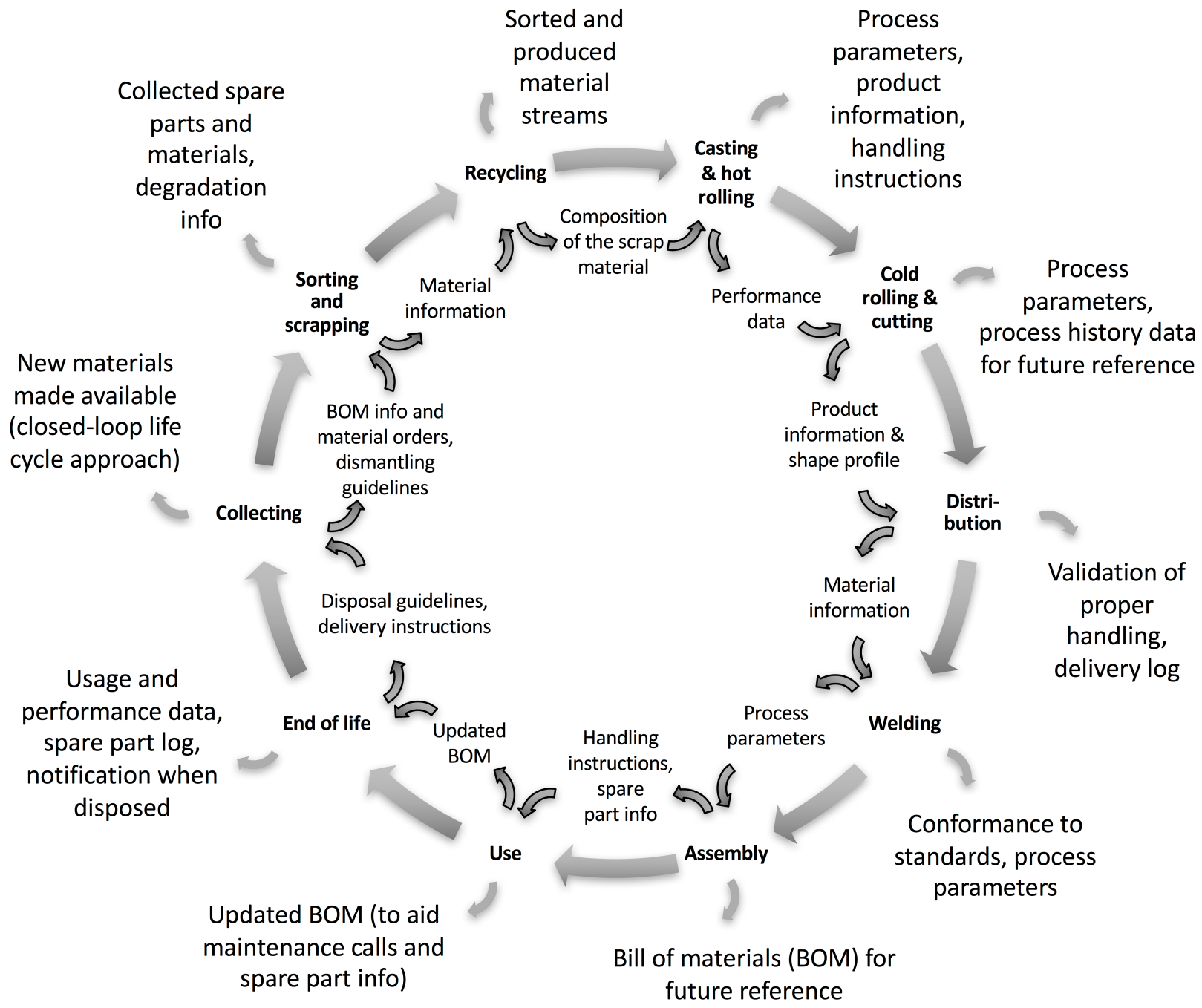

Figure 1. Material intelligence derives from collaborative information sharing throughout the material's life cycle. 
system to function comprehensively, all the actors participating to the life cycle of the product must have an access to the supporting database. The data can be stored either locally at the object or remotely at a supporting database [35], or the data management system can be built to utilize both methods [27]. Naturally, the most suitable identification method is case specific, but the underlining issues remain the same. Considering the long lifespan of steel products, the robustness of the identification is an important issue. The intelligence through network option [35] has many benefits, but the most notable is the possibility to simplify the identification method in the object. If the unique identity is just a simple engraved or printed marking, ensuring the robustness of the identification is considerably easier than with RFID tags or sensor network systems, where the intelligence may be located at the object. For that reason, the simple, but unique items, and a supporting database could be an agreeable solution for all the parties in the industry.

\subsection{Business value of material intelligence}

The role of networks in modern-day economies is increasing. Competition is no longer between companies, but rather between ecosystems [24]. If the information is not shared between the companies, it will result in forming of clusters possessing of rich, but very case specific, information. This development indicates growing potential for utilizing the structural holes in the networks.

Material intelligence enables companies to share information effectively. Our findings suggest that owning excessive amounts of data does not necessarily determine the company's success in the ability to leverage material intelligence. Instead of data protection, the companies should emphasize the potential to turn raw data into something more valuable and on how to utilize that data better than the rivals [15]. This leaves potential to find incentives for systems that enable managing the product life cycle in a closed-loop $[27,40]$ which, in turn, would improve the sustainability of the operation [2].

Our findings emphasize that material intelligence enables business model innovation at the ecosystem level through systemic solutions. As companies initiate information sharing within their ecosystems, they seek for collective value creation possibilities [3]. To the best of our knowledge, current solutions labeled as material intelligence focus on the interest of the focal firm [45] and consider each batch or product type as a homogenous group [14], not individually unique. Since value creation through material intelligence is collective, it also promotes ecosystem-level business model innovations [24]. The companies can become more dynamic and agile when they can respond to changes in their business environment by altering their ecosystems, rather than at the company level.

\subsection{Theoretical contribution}

This paper combines literature from the fields of sociology, business, and organizational sciences, in order to analyze our empirical findings. In addition, we present and refine two important concepts, intelligent materials and material intelligence, in order to incorporate them into IoT-related discussion.

First, to complement the current discussion linking structural holes and firms' business performance $[19,44,49]$, we underline the connection between structural holes and business models, by stating that bridging of structural holes in a company network can be regarded as a way of business model innovation. The case companies aim to bridge the structural holes in the industry networks by using the steel products as message carriers. Furthermore, our empirical material gave indication that the companies seek to create novel business models by identifying and bridging the structural holes in their networks.

Second, our work highlights the potential of the IoT beyond intelligent products. We make the important conclusion that also simple items, such as pieces of steel, can become similarly intelligent, when they are made unique. To date, existing research has studied how products can become intelligent [34,35] and what can be achieved with them [27,28], including product intelligence [33]. The current discussion seems to agree that intelligent products need to be embedded with a certain level of intelligence [33,35,47], whether the decisions happen locally $[28,38]$ or via a remote server $[26,34]$. We suggest that the required level of embedded intelligence should be lowered, in order to incorporate simple, but unique, material objects into the IoT. This would be significant in enabling closed-loop life cycle management of materials and products $[27,28,40]$, which, in turn, would improve material efficiency and sustainability $[2,18]$. Furthermore, it would mean that the product intelligence discourse is extended to apply materials, enabling similar benefits.

Last, we want to refine and provide a more holistic view for material intelligence. In the past, material intelligence has been used to describe a system for materials information management that applies on a product grade level [14]. Similar to the current product intelligence discourse [33], we want to highlight how intelligent materials could enable greater process control by taking account the specific properties of each individual item. As such, material intelligence depicts 
shared, profound understanding of the material properties. This view underlines both potential and need for cross-organizational collaboration.

\section{Conclusion and Limitations}

IoT requires organizations across industries to revise their collaboration opportunities. Cross-organizational collaboration is needed to facilitate the information exchange between companies, which is needed to bridge the structural holes in the networks.

Theory is a process, not a product. Therefore, it can never be finished [20]. Our empirical findings are limited to a single network of actors in a single industry. The SMC concept was new and surprising to some of the interviewed actors. However, this paper aims to provide a nudge in the appropriate direction.

We call for further research and practical tests on how intelligent materials could and should be produced, i.e., what are the best practices for unique markings and respective databases. Also, we would like to see whether material intelligence can spark cross-organizational collaboration in other industries or with other materials. For instance, processing and recycling of plastic might benefit greatly from the exact detailed material data of intelligent materials. In addition, we would like to see further studies testing how structural holes can be utilized in creating new business models.

\section{References}

[1] Ahuja, G. Collaboration networks, structural holes, and innovation: A longitudinal study. Administrative Science Quarterly 45, 3 (2000), 425-455.

[2] Allwood, J.M., Ashby, M.F., Gutowski, T.G., and Worrell, E. Material efficiency: Providing material services with less material production. Philosophical Transactions A 371, 1986 (2013).

[3] Amit, R. and Zott, C. Creating value through business model innovation. MIT Sloan Management Review 53, 3 (2012), 41-49.

[4] Arica, E. and Powell, D.J. A framework for ICT-enabled real-time production planning and control. Advances in Manufacturing 2, 2 (2014), 158-164.

[5] Atzori, L., Iera, A., and Morabito, G. The Internet of Things: A survey. Computer Networks 54, 15 (2010), 2787 2805.

[6] Baines, T., Lightfoot, H., Benedettini, O., and Kay, J. The servitization of manufacturing: A review of literature and reflection on future challenges. Journal of Manufacturing Technology Management 20, 5 (2009), 547-
567.

[7] Borgia, E. The Internet of Things vision: Key features, applications and open issues. Computer Communications $54,(2014), 1-31$.

[8] Burt, R.S. Structural Holes: The Social Structure of Competition. Harvard University Press, Cambridge, 1992.

[9] Burt, R.S. A note on social capital and network content. Social Networks 19, (1997), 355-373.

[10] Burt, R.S. Structural holes and good ideas. The American Journal of Sociology 110, 2 (2004), 349-399.

[11] Dubois, A. and Gadde, L. Systematic combining: An abductive approach to case research. Journal of Business Research 55, (2002), 553-560.

[12] Eisenhardt, K.M. Building theories from case study research. The Academy of Management Review 14, 4 (1989), $532-550$.

[13] Eloranta, V. and Turunen, T. Seeking competitive advantage with service infusion: A systematic literature review. Journal of Service Management 26, 3 (2015), 394425.

[14] Fairfull, A., Warde, S., and Cherns, P. Material Intelligence for Enterprise CAD and PLM. Cambridge, 2016.

[15] Finne, M., Turunen, T., and Eloranta, V. Striving for network power: The perspective of solution integrators and suppliers. Journal of Purchasing and Supply Management 21, 1 (2015), 9-24.

[16] Främling, K., Harrison, M., Brusey, J., and Petrow, J. Requirements on unique identifiers for managing product lifecycle information: Comparison of alternative approaches. International Journal of Computer Integrated Manufacturing 20, 7 (2007), 715-726.

[17] Främling, K., Holmström, J., Ala-Risku, T., and Kärkkäinen, M. Product agents for handling information about physical objects. Technical report. Helsinki University of Technology, 2003.

[18] Främling, K. and McFarlane, D. Editorial. Computers in Industry 60, 3 (2009), 135-136.

[19] García-Muñiz, A.S. and Vicente, M.R. ICT technologies in Europe: A study of technological diffusion and economic growth under network theory. Telecommunications Policy 38, 4 (2014), 360-370.

[20] Glaser, B.G. and Strauss, A.L. The Discovery of Grounded Theory: Strategies for Qualitative Research. Aldine Transaction, 1967.

[21] Gubbi, J., Buyya, R., Marusic, S., and Palaniswami, M. Internet of Things (IoT): A vision, architectural elements, and future directions. Future Generation Computer Systems 


\section{9, 7 (2013), 1645-1660.}

[22] Hargadon, A. and Sutton, R.I. Building an innovation factory. Harvard Business Review 78, 3 (2000), 157-166.

[23] Hinkka, V. and Tätilä, J. RFID tracking implementation model for the technical trade and construction supply chains. Automation in Construction 35, (2013), 405-414.

[24] Iansiti, M. and Levien, R. Strategy as ecology. Harvard Business Review 82, 3 (2004), 68-78.

[25] Kang, S. and Moon, T. Supply Chain Integration and Collaboration for improving Supply Chain Performance: A Dynamic Capability Theory Perspective. 49th Hawaii International Conference on System Sciences, IEEE (2016), 307-316.

[26] Kärkkäinen, M., Holmström, J., Främling, K., and Artto, K. Intelligent products - a step towards a more effective project delivery chain. Computers in Industry 50, 2 (2003), 141-151.

[27] Kiritsis, D. Closed-loop PLM for intelligent products in the era of the Internet of things. Computer-Aided Design 43, 5 (2011), 479-501.

[28] Kubler, S., Derigent, W., Främling, K., Thomas, A., and Rondeau, É. Enhanced product lifecycle information management using "communicating materials." ComputerAided Design 59, (2015), 192-200.

[29] Leiponen, A. and Helfat, C.E. Innovation objectives, knowledge sources, and the benefits of breadth. Strategic Management Journal 31, 2 (2010), 224-236.

[30] Mashal, I., Alsaryrah, O., Chung, T.-Y., Yang, C.-Z., Kuo, W.-H., and Agrawal, D.P. Choices for interaction with things on internet and underlying issues. Ad Hoc Networks $28,(2015), 68-90$.

[31] Matthyssens, P., Vandenbempt, K., and Van Bockhaven, W. Structural antecedents of institutional entrepreneurship in industrial networks: A critical realist explanation. Industrial Marketing Management 42, 3 (2013), 405-420.

[32] Maula, M.V., Keil, T., and Salmenkaita, J.-P. Open innovation in systemic innovation contexts. In $\mathrm{H}$. Chesbrough, W. Vanhaverbeke and J. West, eds., Open Innovation: Researching a New Paradigm. Oxford University Press, Oxford, 2006, 241-257.

[33] McFarlane, D., Giannikas, V., Wong, A.C.Y., and Harrison, M. Product intelligence in industrial control: Theory and practice. Annual Reviews in Control 37, 1 (2013), 69-88.

[34] McFarlane, D., Sarma, S., Chirn, J.L., Wong, C.Y., and Ashton, K. Auto ID systems and intelligent manufacturing control. Engineering Applications of Artificial Intelligence 16, 4 (2003), 365-376.
[35] Meyer, G.G., Främling, K., and Holmström, J. Intelligent products: A survey. Computers in Industry 60, 3 (2009), 137-148.

[36] Nahapiet, J. and Ghoshal, S. Social capital, intellectual capital and the organizational advantage. Academy of Management Review 23, 2 (1998), 242-266.

[37] Porter, M.E. Competitive Strategy: Techniques for Analyzing Industries and Competitors. Free Press, New York, 1980.

[38] Porter, M.E. and Heppelmann, J.E. How smart, connected products are transforming competition. Harvard Business Review 92, 11 (2014), 64-88.

[39] Portes, A. Social capital: Its origins and applications in modern sociology. Annual Review of Sociology 24, (1998), $1-24$.

[40] Ranasinghe, D.C., Harrison, M., Främling, K., and McFarlane, D. Enabling through life product-instance management: Solutions and challenges. Journal of Network and Computer Applications 34, (2011), 1015-1031.

[41] Shapiro, C. and Varian, H. Information rules. Harvard Business School Press, Boston, Massachusetts, 1999.

[42] Teece, D.J. Profiting from technological innovation: Implications for integration, collaboration, licensing and public policy. Research Policy 15, 6 (1986), 285-305.

[43] Ulaga, W. and Reinartz, W.J. Hybrid offerings: How manufacturing firms combine goods and services successfully. Journal of Marketing 75, 6 (2011), 5-23.

[44] Venkatraman, N., Lee, C.-H., and Iyer, B. Interconnect to win: The joint effects of business strategy and network positions on the performance of software firms. In J.A. Baum and T.J. Rowley, eds., Advances in Strategic Management: Network Strategy. JAI Press, 2008, 391-424.

[45] Warde, S., Painter, R., Williams, D., Fairfull, A., and Marsden, W. The business case for materials information technology. Cambridge, 2012.

[46] Whitmore, A., Agarwal, A., and Da Xu, L. The internet of things - a survey of topics and trends. Information Systems Frontiers 17, 2 (2015), 261-274.

[47] Yang, X., Moore, P., and Chong, S.K. Intelligent products: From lifecycle data acquisition to enabling product-related services. Computers in Industry 60, 3 (2009), 184-194.

[48] Yin, R.K. Case Study Research: Design and Methods. Sage Publications, 2009.

[49] Zaheer, A. and Bell, G.G. Benefiting from network position: Firm capabilities, structural holes, and performance. Strategic Management Journal 26, 9 (2005), 809-825. 